\title{
Influence of exchange cations on the catalytic conversion of limonene over Serra de Dentro (SD) and SAz-1 clays Correlations between acidity and catalytic activity/selectivity
}

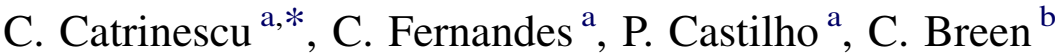 \\ ${ }^{a}$ Centro de Química da Madeira, Dept. Química, Campus da Penteada, 9000-390 Funchal, Portugal \\ ${ }^{\mathrm{b}}$ Materials and Engineering Research Institute, Sheffield Hallam University, Howard Street, Sheffield S1 1WB, UK
}

Received 28 April 2006; received in revised form 8 June 2006; accepted 13 June 2006

Available online 21 July 2006

\begin{abstract}
A bentonite collected at Serra de Dentro (SD), Porto Santo Island, Portugal, and the source clay SAz-1 (Cheto, Arizona) were ion-exchanged with different cations $\left(\mathrm{Al}^{3+}, \mathrm{Ni}^{2+}, \mathrm{Cr}^{3+}\right.$ and $\mathrm{Na}^{+}$). Variable temperature diffuse reflectance infrared Fourier transform spectroscopy (VT-DRIFTS) of pyridine treated samples, thermal desorption of cyclohexylamine and real time mass spectrometry of the evolved gases were used to evaluate the acidic properties of the prepared catalysts. The catalytic activity of these ion-exchanged clays was tested in the acid-catalysed conversion of limonene at $150{ }^{\circ} \mathrm{C}$, to yield isomerization products (terpinolene, $\alpha$-terpinene, $\gamma$-terpinene and isoterpinolene), disproportionation products ( $p$ cymene and $p$-menthenes) and high molecular-weight compounds. The possibility of increasing the selectivity toward $p$-cymene, over a catalyst with substantial Lewis acid character, was particularly envisaged. Catalysts derived from SD were significantly more active than their SAz-1 counterparts. This was mainly attributed to the greater inherent acidity, to the higher structural iron content (providing dehydrogenation activity) and to the higher nitrogen surface area of the starting SD clays. Within the $\mathrm{M}^{n+}-\mathrm{SD}$ series, the order of activity decreased as $\mathrm{Ni}^{2+}>\mathrm{Al}^{3+}>\mathrm{Cr}^{3+}>\mathrm{Na}^{+}$. A direct comparison between $\mathrm{Al}^{3+}-\mathrm{SD}$ (with maximized Brönsted acidity) and $\mathrm{Ni}^{2+}-\mathrm{SD}$ (with predominant Lewis acid character) provided no support for enhanced $p$-cymene production over Lewis acid sites.
\end{abstract}

(C) 2005 Elsevier B.V. All rights reserved.

Keywords: Ion-exchanged clays; Acidity; Catalysis; Limonene; p-Cymene

\section{Introduction}

The use of renewable feedstocks from natural sources is a growing field in which heterogeneous catalysis can offer considerable improvement. The conversion of cheaply available limonene to the more commercially valuable $p$-cymene (for use in fine and speciality chemicals) is a good example, and an extensive review on this topic has recently been published [1]. This conversion requires the migration of the exocyclic double bound into the ring followed by a further ring dehydrogenation.

The presence of acid centres on the catalyst surface is essential in order to isomerize the double bonds in the cyclohexene ring of limonene. Once these conjugated bonds are

\footnotetext{
* Corresponding author. Tel.: +351 291 705119; fax: +351 291705149 .

E-mail address: ccatrine@uma.pt (C. Catrinescu).
}

formed the ring can be aromatized via the dehydrogenation function of the catalyst. The function can be either based on $\mathrm{Cr}_{2} \mathrm{O}_{3}$ [2-4] or Pd [5,6]. The major challenge is the precise control of the acid site strength necessary to minimise secondary reactions, such as polymerization and/or further isomerization of $p$-cymene.

Krishnasamy and Yeddanapalli [2] have shown that an optimum amount of $\mathrm{K}^{+}$ions is required in the $\mathrm{Cr}_{2} \mathrm{O}_{3} / \gamma$ alumina catalyst, to neutralize the strong acid sites. Weyrich et al. [7,8] have used a Ce-promoted Pd/ZSM-5 catalyst which offered both enhanced selectivity towards $p$-cymene and slower catalyst deactivation. The acidity of the host zeolite also had a very significant impact on both the catalytic activity, and the selectivity for $p$-cymene. A second approach uses hydrogenation/dehydrogenation catalysts under reducing conditions. For this process Pd supported on a lowacidity silica support proved to be the most appropriate catalyst $[5,6]$. 
The conversion of $\alpha$-limonene to $p$-cymene has also been achieved using "pure" solid acid catalysts. Two early papers reported that heating limonene in the presence of an acid-treated Japanese clay, resulted in mixtures of products in which the yield of $p$-cymene depended on the reaction conditions [9]. $\mathrm{Na}^{+}, \mathrm{Mg}^{2+}$, $\mathrm{Al}^{3+}$ - and $\mathrm{H}^{+}$-exchanged forms of montmorillonite have been used at selected temperatures in the range of $80-175^{\circ} \mathrm{C}$ and the amount of $p$-cymene produced was reported to be inversely related to the surface acidity of the clay [10]. More recently, De Stefanis and collaborators [11] have compared the catalytic behaviour of alumina-pillared clays (Al-PILC) with that of layered phosphates and zeolites for the conversion of various terpenes. The large-pore zeolite USY was the most active and selective towards $p$-cymene, followed by the most acidic of the Al-PILCs catalysts. The order of reactivity was explained in terms of both surface acidities and shape selectivity.

Fernandes et al. [12] have reported preliminary results concerning the conversion of limonene over a series of acid activated clays, derived from an iron-rich, low-charge bentonite, collected at Serra de Dentro, Porto Santo Island, Portugal, SD bentonite. The results showed that increasing the severity of the acid treatment produced more active catalysts, but the increased catalytic behaviour did not correlate directly with either the calculated surface areas or with the estimated acidity values.

All these studies emphasize the important role of the acidity and active site accessibility, in controlling both the reaction rate and the selectivity towards the desired product. Clay minerals are versatile, environmentally friendly catalysts that can be quite easily tailored to suit a wide variety of organic reactions [13]. Clays are natural minerals that present a range of chemical compositions, locations and density of charge. Consequently, the nature of the clay plays an important role in maximizing the catalytic activity for the precise reaction of interest. Breen and Moronta [14] have studied the correlation of catalytic activity with layer charge for different clays exchanged with active cations. The high layer charge clays (e.g. SAz-1) were not appropriate for reactions in non-polar media, because only those acid sites near the external edges of the gallery were accessible to the reactant(s). Standard charge reduction procedures [15] converted the high-charge montmorillonite into a lower-charge clay, and the hydrated $\mathrm{Al}^{3+}$ cations were able to prop the layers apart and facilitate the catalytic conversion of the non-polar $\alpha$-pinene in the gallery.

The properties of clays can be readily modified by ionexchange, and $\mathrm{Ni}^{2+}$ and $\mathrm{Al}^{3+}$-exchanged montmorillonites are considered "model" Lewis and Brönsted acids, respectively. The nature of the active sites has been probed using FT-IR spectra of adsorbed pyridine [16,17] and supported by catalytic data. The most common test reactions in the current context are: (a) Brönsted acid catalysed rearrangement of $\alpha$-pinene [17-19]; (b) Lewis acid catalysed rearrangement of camphene hydrochloride [17]; (c) Lewis acid catalysed alkylation of toluene with benzyl chloride [19].

Besides acidity and site accessibility, the presence of some transition metal ions (especially $\mathrm{Fe}^{3+}$ ) in the clay structure offers the potential for redox activity. These sites may provide the required dehydrogenation activity and hence play an important role in the overall process. Finally, evolved gas analysis (EGA) of the thermally desorbed products, arising from the degradation of the adsorbed cyclohexylamine (CHA), demonstrated different decomposition pathways over $\mathrm{Al}^{3+}$ - and $\mathrm{Ni}^{2+}$-exchanged $\mathrm{SWy}-2$ clays which could be correlated with the different nature of the active sites [20].

The aim of this study was to evaluate how different interlayer cations $\left(\mathrm{Al}^{3+}, \mathrm{Ni}^{2+}, \mathrm{Cr}^{3+}, \mathrm{Na}^{+}\right)$, selected for their known influence on the acidity and the catalytic activity, influenced the activity of two clays of different origin: a lowcharge clay (SD) of high structural iron content and a highcharge clay (SAz-1) which contains only a small amount of structural iron. A particular focus of the work is to explore how the combination of the transition metals in the clay structure and the exchange cations influence the activity towards $p$ cymene production. Furthermore, the nitrogen surface area of $\mathrm{SD}$ is $>100 \mathrm{~m}^{2} / \mathrm{g}$ which is markedly higher to that of SAz-1 which, at $60 \mathrm{~m}^{2} / \mathrm{g}$ [21], is more representative of most clays. Finally, the possibility that the selectivity towards $p$-cymene could be increased by using a catalyst with substantial Lewis acid character, as suggested by the work of De Stefanis et al. [11], and Crocket and Roduner [22], has been considered.

\section{Experimental}

\subsection{Catalysts}

Porto Santo, a small island that belongs to the Madeira Archipelago, Portugal, contains several deposits of bentonite. The material obtained at Serra de Dentro (SD) was selected as the starting material for further work, since it contains the lowest quantity of impurities within the group of samples collected [23]. The major impurities, $\mathrm{SiO}_{2}, \mathrm{TiO}_{2}$, kaolin and $\mathrm{CaCO}_{3}$, were removed using standard sedimentation procedures before converting the product to the Na-exchanged form using $1 \mathrm{M}$ aqueous sodium chloride solution. Excess $\mathrm{Cl}^{-}$was removed by dialysis. The material obtained is subsequently called $\mathrm{Na}-\mathrm{SD}$ and the elemental composition, cation exchange capacity (CEC), BET surface area and $d$-spacing are reported in Table 1.

Table 1

Chemical composition, surface area and $\mathrm{CEC}$ of $\mathrm{Na}^{+}-\mathrm{SD}$ and $\mathrm{Ca}^{2+}-\mathrm{SAz}-1$

\begin{tabular}{|c|c|c|c|c|c|c|c|c|c|c|c|}
\hline \multirow[t]{2}{*}{ Clay } & \multicolumn{9}{|c|}{ Chemical composition ( $\%$ oxide) } & \multirow[t]{2}{*}{$A_{\mathrm{BET}}\left(\mathrm{m}^{2} / \mathrm{g}\right)$} & \multirow[t]{2}{*}{ CEC (mequiv./100 g) } \\
\hline & $\mathrm{Na}$ & $\mathrm{Mg}$ & $\mathrm{Al}$ & $\mathrm{Si}$ & $\mathrm{K}$ & $\mathrm{Ca}$ & $\mathrm{Ti}$ & $\mathrm{Fe}$ & Others & & \\
\hline SD & 2.6 & 3.4 & 20.5 & 57.4 & 0.9 & 0.5 & 3.3 & 10.3 & 1.1 & 60 & 120 \\
\hline SAz-1 & 0.06 & 6.73 & 19.98 & 59.65 & 0.19 & 3.15 & 0.25 & 1.77 & 0.01 & 130 & 81 \\
\hline
\end{tabular}


DRIFTS spectra and the quantitative XRD profiles of the Na-saturated, purified SD [12] are consistent with a material containing a high percentage of an aluminium rich dioctahedral smectite, with partial isomorphic substitution of $\mathrm{Al}$ by $\mathrm{Mg}$ and $\mathrm{Fe}$ in the octahedral sheets and of $\mathrm{Si}$ by $\mathrm{Al}$ in the tetrahedral sheets. Minor quantities of anatase, kaolin, quartz and cristobalite were present even after the purification procedure.

The $\mathrm{Na}^{+}-, \mathrm{Al}^{3+}{ }_{-}, \mathrm{Ni}^{2+}$ - and $\mathrm{Cr}^{3+}$-exchanged forms were prepared using $1 \mathrm{M}\left(\mathrm{Na}^{+}\right), 0.3 \mathrm{M}\left(\mathrm{Al}^{3+}\right), 0.6 \mathrm{M}\left(\mathrm{Ni}^{2+}\right)$ aqueous chloride solutions and $0.3 \mathrm{M}$ aqueous chromium nitrate solutions. Excess $\mathrm{Cl}^{-}$or $\mathrm{NO}_{3}{ }^{-}$was removed by dialysis. The materials obtained are subsequently referred to as $\mathrm{Na}-\mathrm{SD}$, $\mathrm{Al}-\mathrm{SD}, \mathrm{Ni}-\mathrm{SD}$ and $\mathrm{Cr}-\mathrm{SD}$, respectively. Chemical composition data for the Na-SD identified a substantial amount of calcium, which could not be attributed entirely to an external calcium phase. Further Na-exchange was achieved by mixing $\mathrm{Na}_{3.5}$ EDTA with the clay, stirring the suspension overnight and centrifuging and washing the clay until a stable, low conductivity was obtained in the supernatant. A parallel set of samples was prepared using SAz-1, which was obtained from the Source Clays Repository, Purdue University, USA.

\subsection{Characterization techniques}

Variable temperature diffuse reflectance infrared Fourier transform spectroscopy (VT-DRIFTS), thermal desorption of cyclohexylamine (CHA) and real time mass spectrometry of the evolved gases were used to evaluate the properties of the prepared catalysts. TG data were recorded on a Mettler TG50 thermobalance equipped with a TC10A processor. Samples ( $\sim 10 \mathrm{mg}$ ) were transferred directly out of CHA vapour into the thermobalance and the desorption traces were recorded at a heating rate of $20^{\circ} \mathrm{C}$ under a nitrogen flow of $25 \mathrm{~cm}^{3} / \mathrm{min}$. Samples were conditioned for 15 min under flowing nitrogen to reduce the amount of physisorbed CHA. For VT-DRIFTS the samples were dried in air at $60{ }^{\circ} \mathrm{C}$ overnight, prior to exposure to vapour phase pyridine for periods in excess of $72 \mathrm{~h}$. The samples were transferred to the environmental chamber (Graseby-Specac; maximum operating temperature $500{ }^{\circ} \mathrm{C}$ ), and the spectra were collected. The first spectrum was collected before purging at $25{ }^{\circ} \mathrm{C}$ then after purging for at least $15 \mathrm{~min}$. The sample was then heated to $50{ }^{\circ} \mathrm{C}$ and allowed to equilibrate for $15 \mathrm{~min}$ before collecting the spectrum. This process was repeated to $200{ }^{\circ} \mathrm{C}$ at $25^{\circ} \mathrm{C}$ increments and then to $500{ }^{\circ} \mathrm{C}$ at $50{ }^{\circ} \mathrm{C}$ increments. Background spectra, collected using $\mathrm{KBr}$ under the same conditions, were used to ratio against the respective sample spectra. The spectrometer used was a Mattson Polaris operating at $4 \mathrm{~cm}^{-1}$ resolution and 256 scans. Evolved gas analysis (EGA) was conducted using a Thermo Unicam Synergic chemical analysis system (TG-MS) equipped with a Cahn TG 131 thermobalance. Clay-CHA samples (ca. $20 \mathrm{mg}$ ) were placed in a quartz crucible and pretreated for $15 \mathrm{~min}$ at $25^{\circ} \mathrm{C}$ under a flow of nitrogen at atmospheric pressure before being heated from 25 to $800{ }^{\circ} \mathrm{C}$ at $20^{\circ} \mathrm{C} / \mathrm{min}$ in the same nitrogen flow. This removed the entire physisorbed base, which is why there was no weight loss or mass spectral response below $50{ }^{\circ} \mathrm{C}$. The evolved gases were then transferred from the TG to the MS (Automass System 2, Unicam) via a silica-lined stainless steel, transfer line, maintained at $200{ }^{\circ} \mathrm{C}$, which ensured immediate sampling and minimised dilution effects. During "real time" TG-MS analysis, the mass spectrometer scanned 4-500 u every $1.5 \mathrm{~s}$.

\subsection{Catalytic tests}

Limonene and $n$-dodecane were dried over anhydrous magnesium sulphate prior to use. Reactions were performed in a stirred $25 \mathrm{ml}$ batch reactor, equipped with a reflux condenser, under drying tube $\left(\mathrm{CaCl}_{2}\right)$ protection. The stirrer speed was chosen to ensure that reaction rates were not under diffusion control.

Before the test reaction, $100 \mathrm{mg}$ of catalyst was thermally activated at the prescribed temperature under air, in the reaction vessel before being allowed to cool. This operation was performed under dry conditions to avoid any contact with atmospheric humidity. A limonene/internal standard mixture comprising $10 \mathrm{ml}$ of limonene and $2 \mathrm{ml}$ of $n$-dodecane, was injected over the dried catalyst. The reaction conditions were $15 \mathrm{~min}$ at $150{ }^{\circ} \mathrm{C}$. Samples were taken at selected time intervals, separated using a syringe filter and stored in dry sample vials. The filter had no influence on the reaction products and no further reaction occurred during storage. The products were identified by GC-MS (Varian Saturn 3) and quantified by capillary GC with FID detection.

\section{Results and discussion}

\subsection{Acidity measurements}

\subsubsection{DRIFTS studies}

VT-DRIFTS of pyridine treated samples still remains the only routine way to unequivocally distinguish between Brönsted and Lewis acid sites on the surface of solid acid catalysts [16]. It has been shown [24] that peaks at 1635 and $1540 \mathrm{~cm}^{-1}$ can be assigned to the pyridinium ion (Brönsted acidity, BPYR), whereas peaks at 1613 and $1450 \mathrm{~cm}^{-1}$ are diagnostic for pyridine co-ordinately bound to Lewis acid sites (LPYR) while peaks at 1596 and $1440 \mathrm{~cm}^{-1}$ may report the presence of H-bonded pyridine (HPYR). All these species contribute intensity to the $1490 \mathrm{~cm}^{-1}$ band although the largest contribution at higher temperatures $\left(>120{ }^{\circ} \mathrm{C}\right)$ is from BPYR. In accordance with previous studies on a different bentonite [25] $\mathrm{Al}^{3+}{ }_{-}$-SD exhibited bands associated with BPYR (and some LPYR), $\mathrm{Ni}^{2+}$-SD exhibited bands associated with LPYR whereas the spectra for pyridine treated $\mathrm{Cr}^{3+}$-SD contained bands for both BPYR and LPYR (Fig. 1).

Fig. 1 presents the VT-DRIFTS spectra of the air-dried $\mathrm{M}^{n+}$ SD clays, following exposure to pyridine and subsequent evacuation at increasing temperatures. The pyridine-treated $\mathrm{Ni}^{2+}$-SD sample, heated at $50{ }^{\circ} \mathrm{C}$, provided evidence for significant amounts of physisorbed pyridine (1440 and $1596 \mathrm{~cm}^{-1}$ ). Degassing at $100{ }^{\circ} \mathrm{C}$ caused a marked reduction in the intensity of both the 1440 and $1596 \mathrm{~cm}^{-1}$ bands, which by $150{ }^{\circ} \mathrm{C}$ had disappeared. A weak, broad band at $1540 \mathrm{~cm}^{-1}$, 

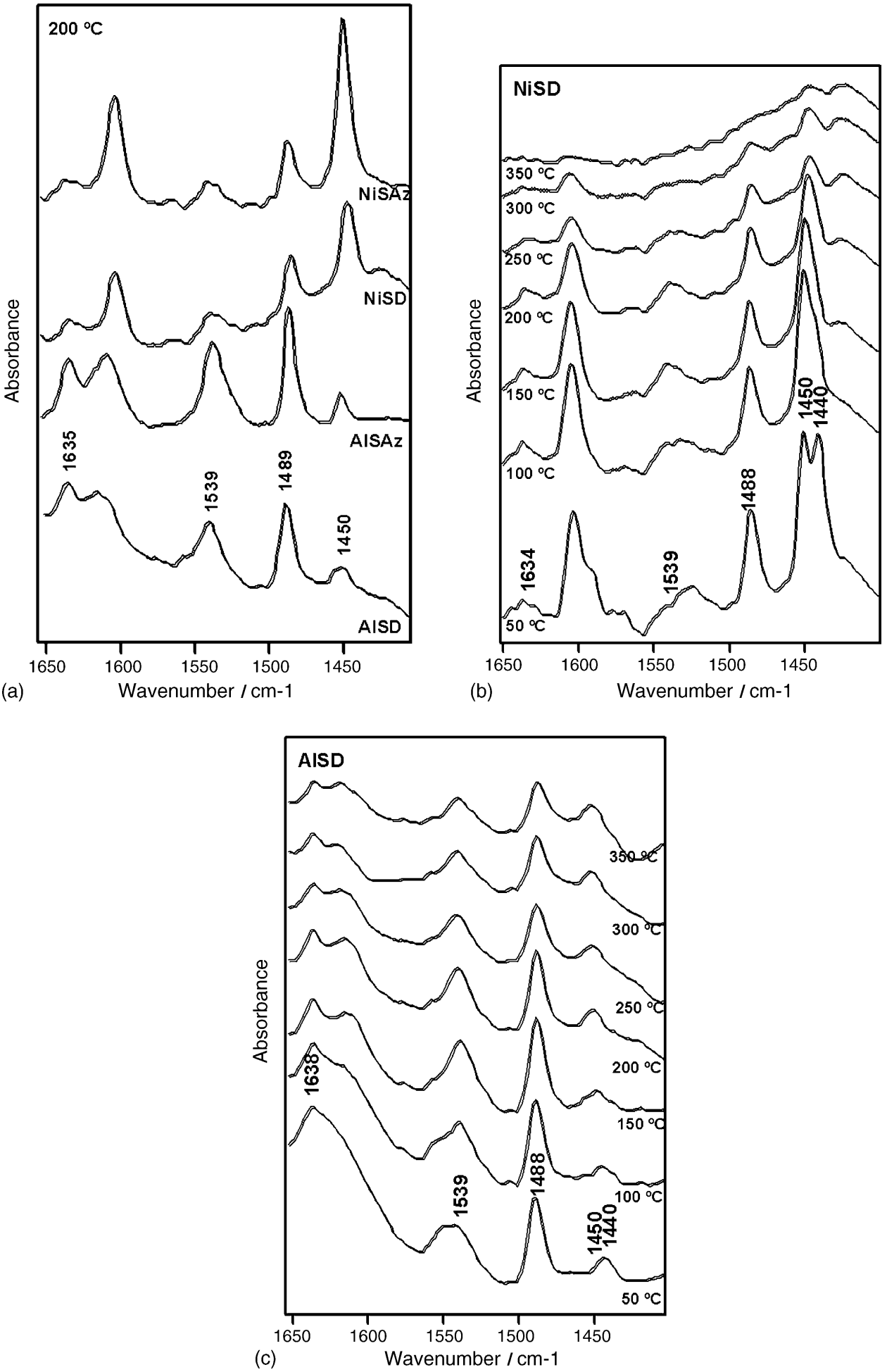

Fig. 1. . DRIFTS spectra of: (a) air-dried $\mathrm{M}^{n+}{ }_{-}$SD clays, following exposure to pyridine and subsequent heating to $200{ }^{\circ} \mathrm{C}$; pyridine-treated, (b) $\mathrm{Ni}^{2+}{ }_{-} \mathrm{SD}$ and (c) $\mathrm{Al}^{3+}{ }_{-}$ SD heated to the temperatures indicated.

diagnostic for Brönsted bound pyridine (BPYR), appeared as an unresolved shoulder at $50{ }^{\circ} \mathrm{C}$, which remained present up to $200{ }^{\circ} \mathrm{C}$ but became increasingly weaker above this temperature. In contrast, high temperature activation of the pyridine-treated $\mathrm{Ni}^{2+}$-SD, did not remove the band at $1450 \mathrm{~cm}^{-1}$ and the $1613 \mathrm{~cm}^{-1}$ band which are considered diagnostic for LPYR.
The spectrum recorded at $50{ }^{\circ} \mathrm{C}$ for the pyridine-treated $\mathrm{Al}^{3+}$-form of SD, exhibited a much broader envelope of peaks in the $1570-1650 \mathrm{~cm}^{-1}$ region, together with a weak band at $1450 \mathrm{~cm}^{-1}$ but there was little evidence for large amounts of physisorbed pyridine $\left(1440\right.$ and $\left.1596 \mathrm{~cm}^{-1}\right)$. In contrast to $\mathrm{Ni}^{2+}-\mathrm{SD}$, a well-defined, intense BPYR band at $1539 \mathrm{~cm}^{-1}$, 
together with the $1488 \mathrm{~cm}^{-1}$ band, dominated these spectra. The generation of Lewis acid sites, subsequent to heating above $150{ }^{\circ} \mathrm{C}$, was supported by the presence of two distinct bands at 1450 and $1613 \mathrm{~cm}^{-1}$, typically attributed to LPYR.

Despite the difficulty of obtaining quantitative information, the truly remarkable feature of these spectra was the overall dominance of bands associated with LPYR in $\mathrm{Ni}^{2+}-\mathrm{SD}$ in contrast to $\mathrm{Al}^{3+}$-SD in which a well-defined, intense BPYR band appeared at $1540 \mathrm{~cm}^{-1}$. Indeed, the fact that the 1540 and $1490 \mathrm{~cm}^{-1}$ bands were still present at $350{ }^{\circ} \mathrm{C}$ emphasizes the strength of the Brönsted acid sites on $\mathrm{Al}^{3+}$-SD. It is important to note that the comments regarding $\mathrm{Al}^{3+}-\mathrm{SD}$ and $\mathrm{Ni}^{2+}-\mathrm{SD}$ are equally relevant to these cation-exchanged forms of SAz-1.

Although the spectra obtained from the $\mathrm{Al}^{3+}-\mathrm{SAz}$ sample exhibited sharper and better defined peaks than the corresponding sample derived from SD which probably indicates a more uniform distribution of the acid site strength on $\mathrm{SAz}$ than on SD. The homoionic Na-exchanged forms presented different results: $\mathrm{Na}^{+}-\mathrm{SAz}$ showed little to no evidence of BPYR or LPYR, whereas $\mathrm{Na}^{+}-\mathrm{SD}$ exhibited small but discernible bands assigned to BPYR and LPYR (not illustrated). This is consistent with both the thermogravimetric and catalytic studies referred to below.

\subsubsection{Thermogravimetric (TG) studies}

It has been suggested that the thermal desorption of cyclohexylamine can be used to quantify the number of acid sites on a clay catalyst [26]. The technique requires the determination of the weight loss between 280 and $440{ }^{\circ} \mathrm{C}$ and
Table 2

Quantities of CHA desorbed in the 280 and $440{ }^{\circ} \mathrm{C}$ temperature interval together with the temperature of the maximum in the derivative thermogram

\begin{tabular}{lll}
\hline Clay & CHA desorbed $(\mathrm{mol} / \mathrm{g})$ & DTG maximum $\left({ }^{\circ} \mathrm{C}\right)$ \\
\hline Al-SD & 1.35 & 350 \\
Cr-SD & 1.33 & 350 \\
Ni-SD & 1.21 & 350 \\
Ca-SD & 1.15 & 350 \\
Na-SD & 0.54 & 350 \\
Al-SAz & 1.42 & 320 \\
Ni-SAz & 1.28 & 360 \\
Ca-SAz & 1.27 & 310 \\
Na-SAz & 0.13 & 350 \\
\hline
\end{tabular}

its conversion to the number of mmol of CHA desorbed. The relative ease of obtaining this quantity has popularised its use even though the value obtained does not distinguish between cyclohexylamine bound to Brönsted or Lewis acid sites. Moreover, the method often reports high acidity values which are not substantiated by the yields obtained in the associated tests of catalytic activity. For example, the presence of $\mathrm{Ca}^{2+}$ ions, which retain $\mathrm{CHA}$ to temperatures at which thermal $\mathrm{C}-\mathrm{N}$ bond cleavage occurs, can lead to a spurious acidity value [27]. The quantities of CHA desorbed in the appropriate temperature interval are presented in Table 2.

As expected, $\mathrm{Na}^{+}-\mathrm{SAz}$ exhibited a very weak peak at $350{ }^{\circ} \mathrm{C}$ (0.13 mmol CHA g $\left.{ }^{-1}\right)$, but $\mathrm{Na}^{+}$-SD presented a more intense peak than expected for a $\mathrm{Na}^{+}$-exchanged clay $(0.54 \mathrm{mmol}$ CHA $\mathrm{g}^{-1}$ ). This relatively high amount of CHA desorbed by the $\mathrm{Na}^{+}$-SD sample concurs with the DRIFTS spectra and is

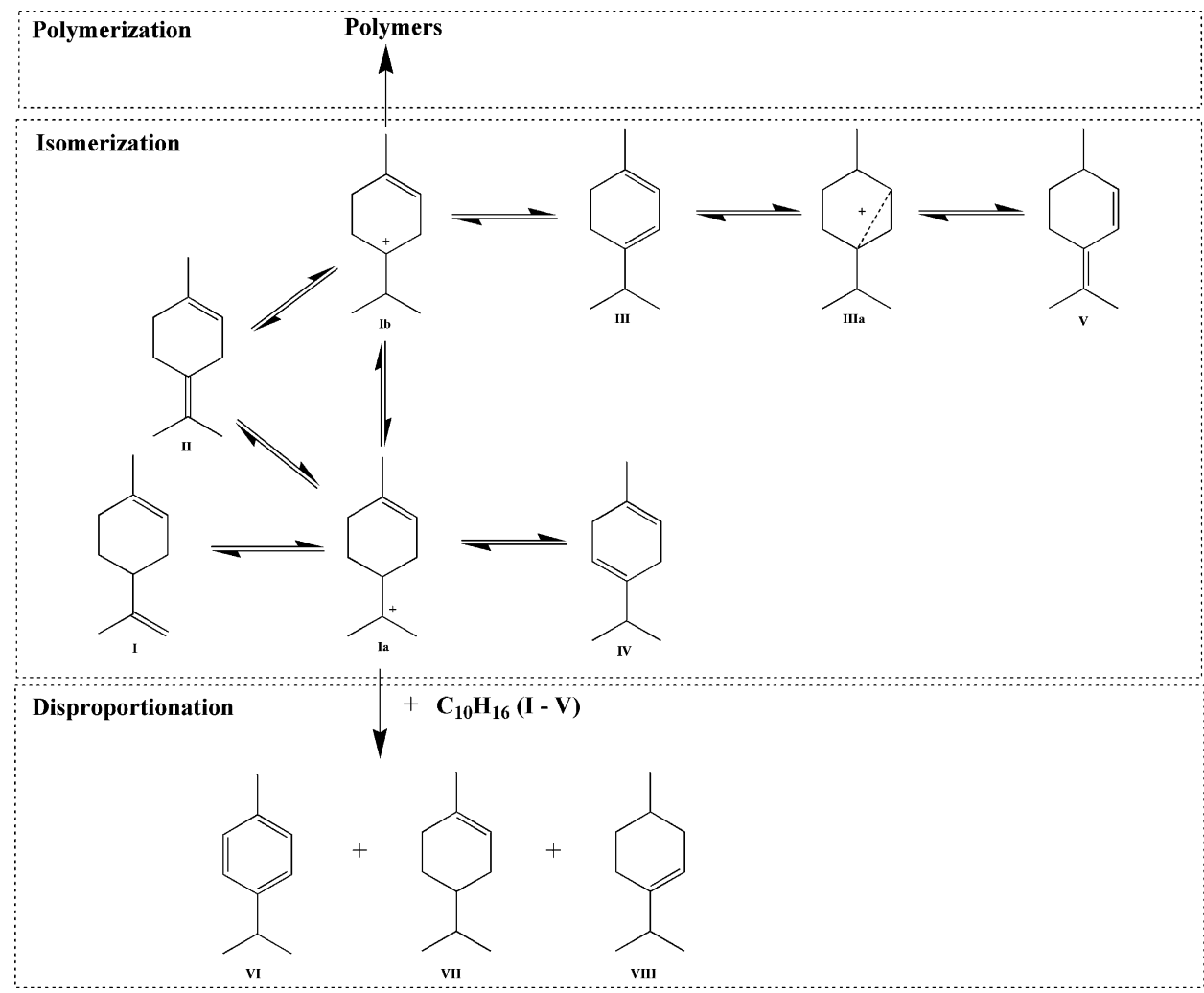

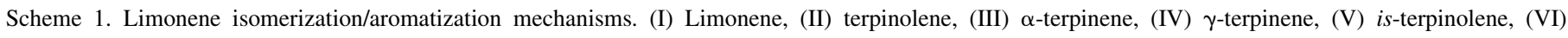
p-cymene, (VII) 1-p-menthene and (VIII) 3-p-menthene. 
further supported by the catalytic test results. With the exception of the $\mathrm{Na}^{+}$forms, the SD clays generally desorb lower quantities of CHA than the equivalent SAz-1 samples, which correlated well with the difference in CEC between SAz1 (120 mequiv./100 g) and SD (80 mequiv./100 g).

\subsection{Catalytic results}

In the presence of acid or, in this case, acidic centers existing on the clay surface, limonene reacts to form a mixture of products (Scheme 1). Fig. 2 uses the catalytic test results obtained over $\mathrm{Al}^{3+}-\mathrm{SD}$, following pretreatment at $150{ }^{\circ} \mathrm{C}$, to illustrate how the total conversion and the product distribution varied with time. The overall shape of the curves was the same, although differing in time and yield, over clay exchanged with other cations or activated at different temperatures.

Under these reaction conditions, three competitive reactions take place: (1) isomerization, (2) disproportionation to equimolar quantities of $p$-cymenes and $p$-menthenes and (3) polymerization. Examination of the hydrogen shift reactions reveals that the process could be formally divided into three stages. In the early part of the reaction (stage I) there was a steep decrease in limonene concentration (zero-order kinetics) accompanied by the production of the main reaction intermediates. The initial reaction rates decreased in the order: terpinolene $>\alpha$-terpinene
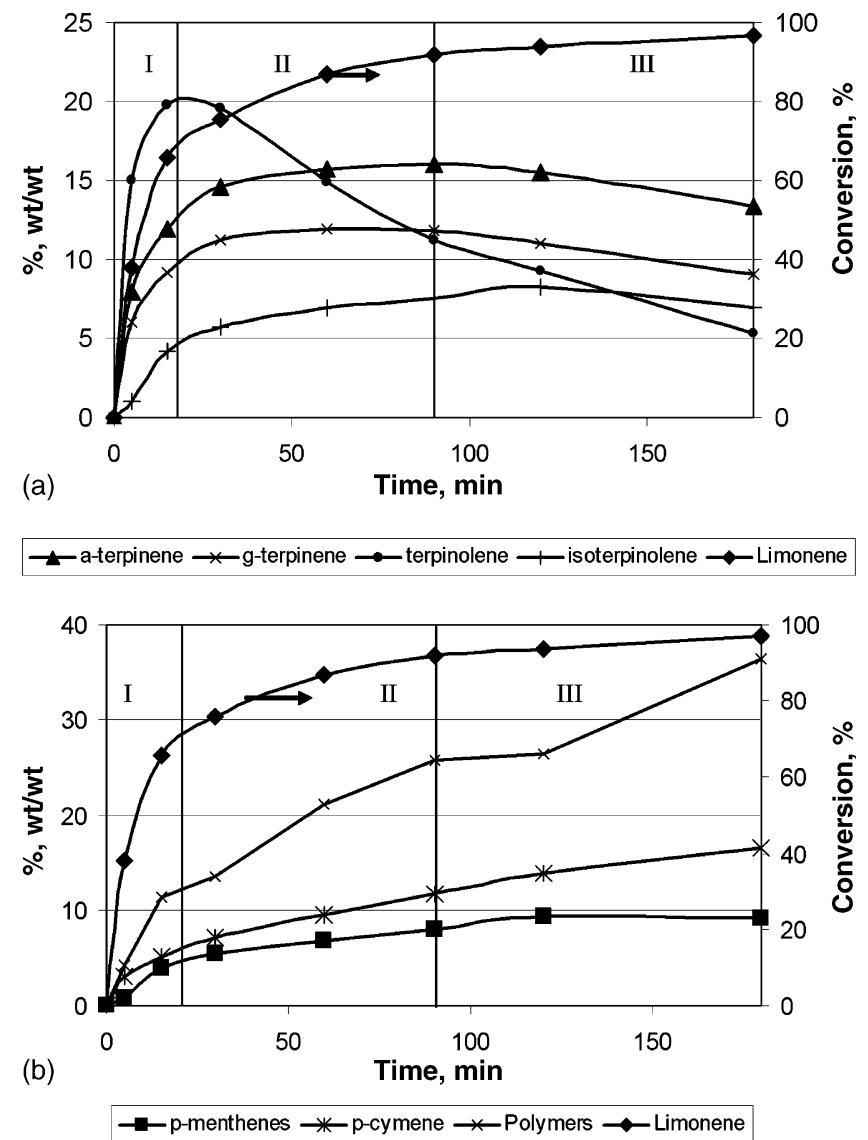

Fig. 2. Product distribution during the conversion of limonene at a reaction temperature of $150{ }^{\circ} \mathrm{C}$ using $\mathrm{Al}^{3+}$-SD. (a) Isomerization products and (b) other products (disproportionate, polymerization). $>\gamma$-terpinene $>$ isoterpinolene. The linear decrease in limonene concentration terminated as the concentration of terpinolene reached a maximum (end of stage I, 70\% limonene conversion), after which the consumption of terpinolene followed zero-order kinetics whereas the concentrations of $\alpha$-terpinene and $\gamma$ terpinene remained essentially constant (stage II). During stage III, which occurred at $\geq 90 \%$ limonene conversion, the content of all dienes in the mixture decreased continuously, until their complete disappearance at prolonged reaction time $(\geq 10 \mathrm{~h})$. Fig. $2 b$ presents the distribution of the products arising from a more extensive (than isomerization) transformation of the $p$-menthadienes. Clearly, both the disproportionation and polymerization processes began during stage I but, unlike the isomerization products, which reached a plateau, the yields of $p$-cymene, menthenes and polymeric species continued to increase throughout stages II and III.

The formation of similar amounts of $p$-cymene and $p$ menthenes suggested that $p$-cymene was formed mainly via the disproportionation of hydrogen in the dienes. In the late stages of the reaction, the concentration of $p$-cymene increased slightly, while the $p$-menthenes content remained almost constant. This increase in $p$-cymene/ $p$-menthenes molar ratio could indicate that hydrogen redistribution was taking place between a $p$-menthadiene and a polymeric species or that the aromatic molecule was produced through an additional oxidation mechanism (on acid Lewis sites). The polymerization process dominated stage III, as the content of the dienes with conjugated double bonds ( $\alpha$-terpinene and isoterpinolene) reached a maximum. Their condensation, via a Diels-Alder process, led to the formation of high molecular weight products, reaching up to $60 \%(\mathrm{w} / \mathrm{w})$ at the end of the process.

Fig. 3, which presents the distribution of products (15 min at $150{ }^{\circ} \mathrm{C}$ ) over $\mathrm{Al}^{3+}$-SD pretreated at different temperatures, reinforces the generally accepted view that the acid character of an $\mathrm{Al}^{3+}$-exchanged montmorillonite is strongly dependent on the thermal activation procedure. The filled diamonds present the limonene conversion values, which provide a visual indication of the progress of the reaction (in conjunction with Fig. 2). The low conversion of limonene over $\mathrm{Al}^{3+}{ }_{-} \mathrm{SD}$ (hydrated) indicates that the rate over this catalyst was quite slow and thus positions these results in the early part of stage I
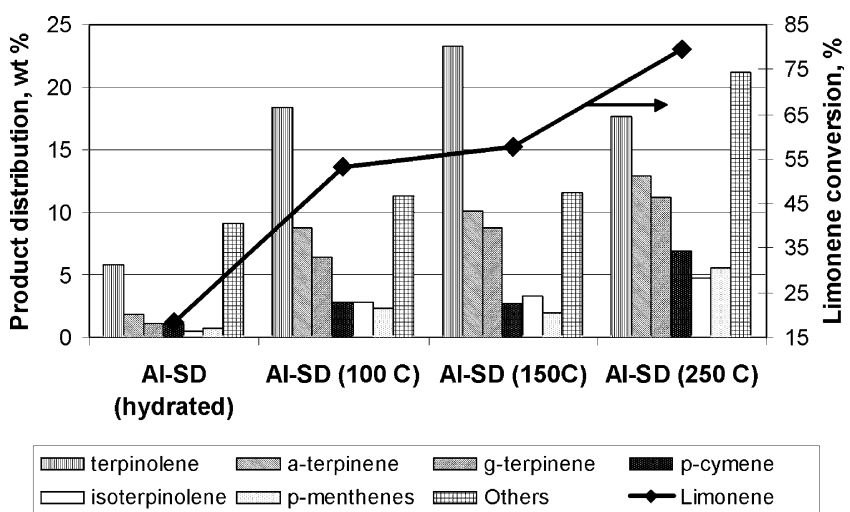

Fig. 3. The influence of activation temperature on the product distribution over $\mathrm{Al}^{3+}$-SD. 
in Fig. 2, whereas a limonene conversion of $80 \%$ indicates that the reaction over $\mathrm{Al}^{3+}-\mathrm{SD}\left(250{ }^{\circ} \mathrm{C}\right)$ had progressed much further during the $15 \mathrm{~min}$ time period and was entering stage II. Hence, the reaction rate over the individual catalysts increased from left to right across Fig. 3. The deliberately hydrated sample ( $\mathrm{Al}^{3+}-\mathrm{SD}$ (hydrated); Fig. 3) displayed a very low catalytic activity, suggesting that the acid sites were blocked by water making them inactive towards the reactants. Increasing the pretreatment temperature to $100{ }^{\circ} \mathrm{C}$, caused a marked increase in activity, whereas only a slight increase in activity was observed between 100 and $150{ }^{\circ} \mathrm{C}$. Increasing the thermal activation temperature above $150{ }^{\circ} \mathrm{C}$, caused a reduction in the Brönsted acidity and an increase in the Lewis acidity in accordance with the model in which the exchange ions become Lewis acidic, as the directly coordinated water is driven off (Fig. 1c). Therefore, a pretreatment temperature of $150{ }^{\circ} \mathrm{C}$ was selected to avoid the uncertainty regarding the Brönsted/Lewis acid balance and to take advantage of the reduced amount of polymer production.

Fig. 4a illustrates the distribution of products obtained over $\mathrm{Ni}^{2+}-, \mathrm{Al}^{3+}$ - and $\mathrm{Cr}^{3+}$-exchanged $\mathrm{SD}$ in comparison with the benchmark (nominally inactive) $\mathrm{Na}^{+}-\mathrm{SD}$ after 15 min reaction at $150{ }^{\circ} \mathrm{C}$. The low conversion of limonene over $\mathrm{Na}^{+}-\mathrm{SD}$ indicated that the rate over $\mathrm{Na}^{+}-\mathrm{SD}$ was quite slow, placing the results in the early part of stage I (Fig. 2), whereas the limonene conversion of $70 \%$ indicated that the reaction over $\mathrm{Ni}^{2+}-\mathrm{SD}$ had entered stage II. Hence, the reaction rate over the individual catalysts increased from left to right across Fig. 4a. It is
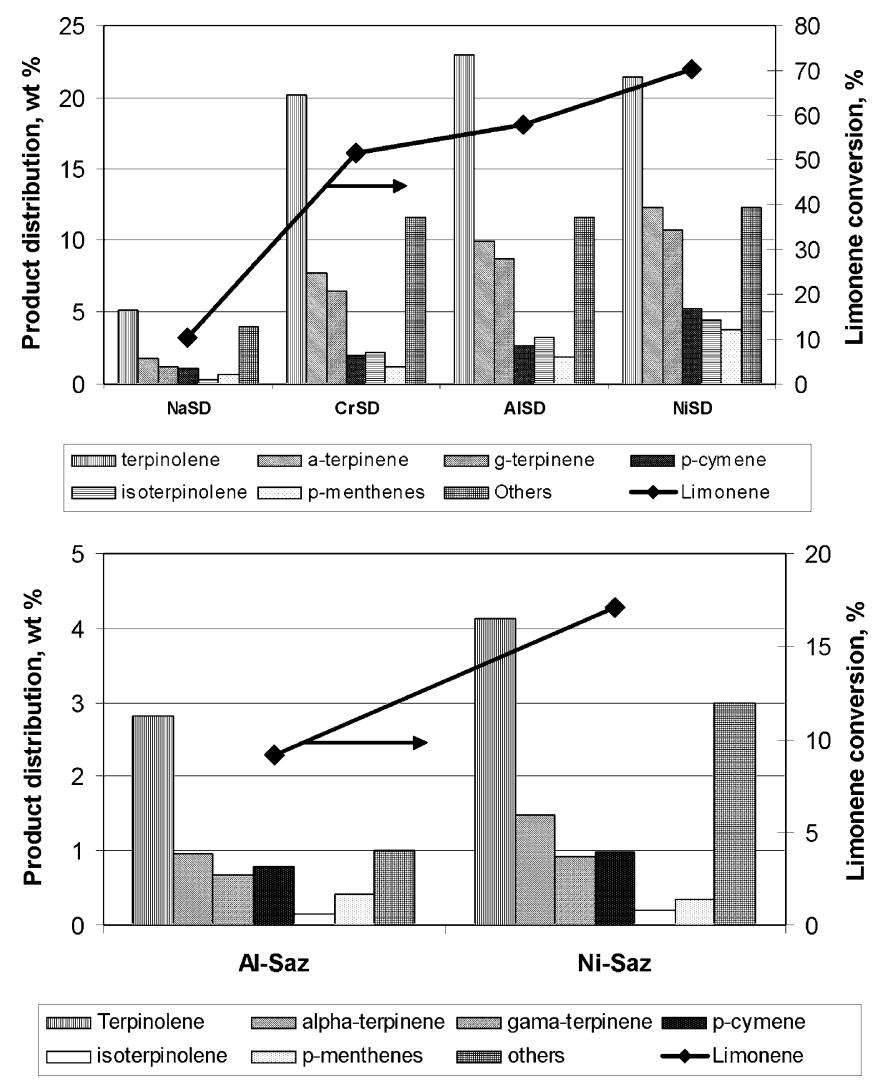

Fig. 4. The influence of the exchange action on limonene conversion and product distribution for: (a) SD and (b) Sass derived catalysts. important to note that the polymer yield after 15 min over $\mathrm{Al}^{3+}-$, $\mathrm{Cr}^{3+}$ - and $\mathrm{Ni}^{2+}$-exchanged SD did not exceed $12 \mathrm{wt} \%$ and the maximum yield of $p$-cymene, as well as $\alpha$ - and $\gamma$-terpinene, was obtained over $\mathrm{Ni}^{2+}-\mathrm{SD}$.

Fig. $4 \mathrm{~b}$ reports the dramatically reduced activity over $\mathrm{Al}^{3+}$ and $\mathrm{Ni}^{2+}$-exchanged $\mathrm{SAz}-1$. Once again, the $\mathrm{Ni}^{2+}$-exchanged form was more active than the Al-form but it produced a significantly higher relative yield of polymeric products. Overall, the rate of limonene conversion over SD and SAz-1 was low compared with that observed over acid-activated SD which produced $>90 \%$ conversion after $15 \mathrm{~min}$ at $80{ }^{\circ} \mathrm{C}$ [12]. The yields of $p$-cymene were also higher over the acid clays reaching $14 \%$ with the optimized acid-activated SD. However, the yield of polymeric species was also greatly enhanced when the acid treated clays were used, reaching $50 \%$ of the total conversion. In general, the cation-exchanged forms of SD used here produced yields comparable with mildly acid activated $\mathrm{SD}$, but offer the advantage of significant reductions in the production of polymeric species and therefore a cleaner product liquor.

Catalytic activities over clays, whether they arise from Brönsted or Lewis acidity, generally correlate with the exchange capacity of the base clay, provided the reactant can enter the gallery. Consequently, it is reasonable to anticipate that SAz-1 would provide more acid sites than similarly exchanged SD samples, although a valid counter argument would identify the potential lack of space to accommodate the limonene in the gallery of SAz-1 due to the greater density of exchange cations required to compensate the higher exchange capacity of SAz-1. Thus, the extremely low activities reported for $\mathrm{Ni}^{2+}$ - and $\mathrm{Al}^{3+}$-exchanged $\mathrm{SAz}-1$ in Fig. $4 \mathrm{~b}$ indicate that, although the SAz-1 clays should have a higher acidity than the SD clays, only a very small fraction of these sites was accessible to the reactant, limonene. A realistic rationalization of this observation is that only the sites located at the periphery of the gallery or on the external surface of the clay are accessible to the non clay-swelling reactant whilst the interlamellar regions would be more readily accessed by more polar species capable of entering the gallery.

The much enhanced activity of the SD derived catalysts may result from their high surface areas, which approach $130 \mathrm{~m}^{2} / \mathrm{g}$. Moreover, the acidity and the catalytic activity displayed by $\mathrm{Na}^{+}$-exchanged SD suggest that non-exchangeable acid sites (defect sites or edge sites) on SD are more active than those on $\mathrm{SAz}$, and could play an important role in the sequence of catalytic events. It is also possible that the high iron content of SD provides the opportunity for electron transfer reactions, which may contribute to the overall activity.

Although these results support the fact that accessibility to the active site is an important feature for reactions involving non-polar reagents, the nature of the catalyst's acidity should also be considered to arrive at a more detailed understanding of the process. The evolution of the reaction products in time (Fig. 2) is typical for acid catalysts and was comparable to results reported for several liquid and solid acids (silica and acid forms of ion-exchange resins) [28]. The transformation of limonene (and other terpenes) is usually attributed to Brönsted 


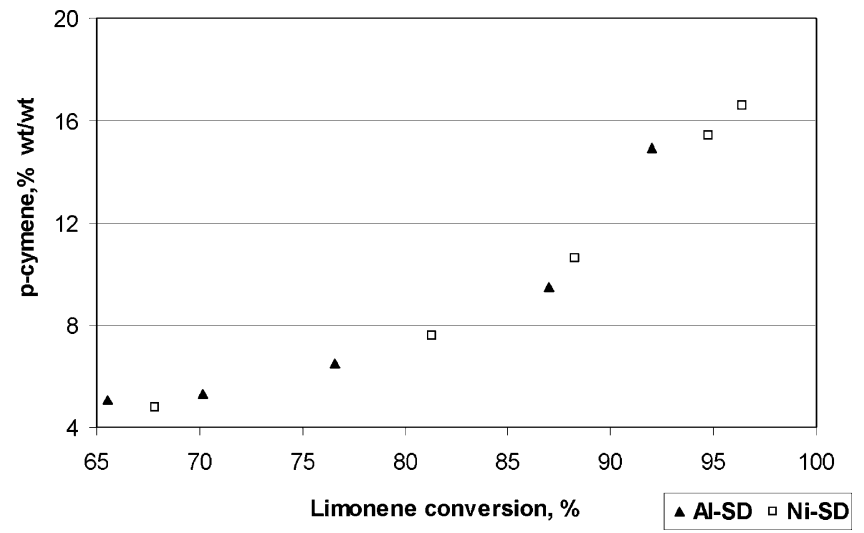

Fig. 5. $p$-Cymene content in the final mixture over $\mathrm{Al}^{3+}-\mathrm{SD}$ and $\mathrm{Ni}^{2+}-\mathrm{SD}$ presented as a function of limonene conversion.

sites, which protonate the unsaturated molecule, thus initiating a network of reactions (Scheme 1), including dehydrogenation and polymerization. Hölderich et al. [7] studied the conversion of limonene at $200-300{ }^{\circ} \mathrm{C}$, over acidic H-ZSM-5 and USY zeolites. They identified the same reaction products, pointing out that, for acidic catalysts, many side and consecutive reactions occur, forming Diels-Alder products, polymers and coke. Furthermore, the presence of strong acid sites was considered critical for the formation of the aromatic moiety. Frenkel and Heller-Kallai [10] have reported similar trends over $\mathrm{H}^{+}$- and $\mathrm{Al}^{3+}$-exchanged montmorillonite from Makhtesh Ramon (Israel). However, these authors only provided a simplified picture of the process, considering the sum of all menthadienes instead of the individual isomers and underestimating the extent of the polymerization process. Although no information regarding the thermal activation procedure for the ion-exchanged clays was given, and the acidity was evaluated using Hammett indicators, some trends could be discerned. Thus, as the surface acidity increased: (i) the rate of limonene consumption increased and (ii) the concentration of isomerization and disproportionation products reached a maximum after shorter reaction times.
However, there is evidence [22] that the conversion of some terpenes ( $\alpha$-pinene, trans-isolimonene and $\alpha$-terpinene) over zeolites may not be catalysed by Brönsted acid sites. These authors used deuterated mordenite as the catalyst but were unable to find any deuterium incorporated in the starting terpene leading them to suggest that the rearrangements occurred over Lewis acid sites. Moreover, electron paramagnetic resonance (EPR) studies, have shown that the incorporation of the three terpenes (listed above) in mordenite give rise to the same radical cation, i.e that of $\alpha$-terpinene. Thus, a Lewis acid site could behave as an "electron hole" and accept one electron from the electron-rich terpene, giving rise to the corresponding radical cation, which undergoes further conversion to the more stable $\alpha$-terpinene radical cation. Furthermore, De Stefanis et al. [11] have also shown that $\alpha$-pinene and limonene are readily converted over zeolites and PILCs, under Lewis acid conditions, with USY exhibiting a high selectivity $(>40 \%)$ towards $p$-cymene, the oxidation product of limonene. This suggestion of Lewis acid catalyst prompted the authors to consider the evidence for and evaluate the possibility that the selectivity towards $p$-cymene could be enhanced by using clays with Lewis acid character.

The product distribution for SD clays (Fig. 4a), exchanged with $\mathrm{Al}^{3+}, \mathrm{Ni}^{2+}, \mathrm{Cr}^{3+}$ and $\mathrm{Na}^{+}$, show that the conversion decreased as $\mathrm{Ni}^{2+}>\mathrm{Al}^{3+}>\mathrm{Cr}^{3+}>\mathrm{Na}^{+}$. This trend, which was also observed for the SAz based catalysts (Fig. 4b), is different to that observed in Brönsted acid catalysed reactions, where ions with a high charge-to-radius ratio $(\mathrm{Al}=0.021)$ are more active that those with lower ratios (e.g., $\mathrm{Ni}=0.016)$. It has been previously demonstrated [16] and further confirmed by the VTDRIFTS data presented here (Fig. 1) that $\mathrm{Al}^{3+}$-exchanged clays, activated between 120 and $150{ }^{\circ} \mathrm{C}$, displays a high concentration of Brönsted acid sites, and are often considered to be model Brönsted catalysts. This is due to the high polarization of water molecules in the primary coordination sphere of the small, highly polarizing $\mathrm{Al}^{3+}$ cations, which results in the generation of acidic protons. However, it is important to note that a

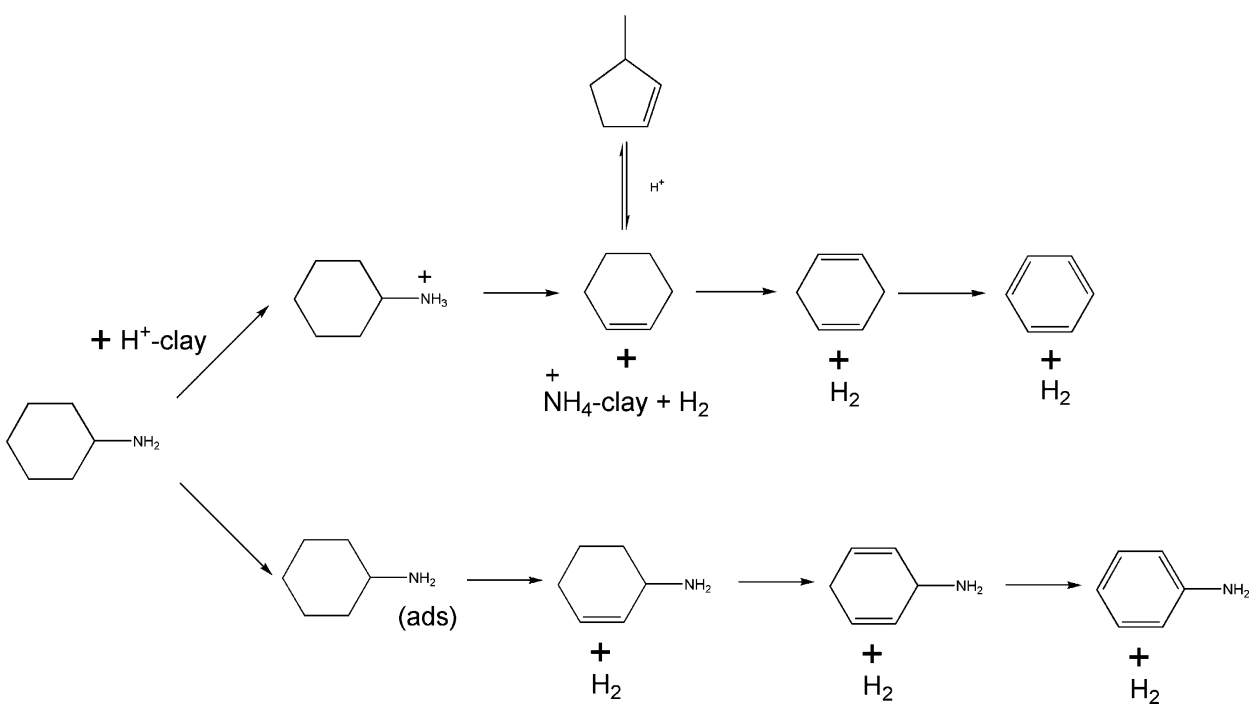

Scheme 2. Decomposition mechanism for acid controlled CHA degradation. 
significant number of Lewis acid sites were also present on the surface of $\mathrm{Al}^{3+}-\mathrm{SD}$ after heating the sample to $200{ }^{\circ} \mathrm{C}$, as revealed by DRIFTS spectra of adsorbed pyridine (Fig. 1), although they may not be accessible to limonene. In contrast, $\mathrm{Ni}^{2+}$-exchanged clays exhibit considerable Lewis acid character, even after low-temperature activation. Under these conditions, $\mathrm{Ni}^{2+}$ ions on the clay surface retain vacant coordination sites, allowing them to coordinate Lewis bases. More precisely, Velghe et al. [29] found that, after activation at $140{ }^{\circ} \mathrm{C}$, a portion of the exchangeable $\mathrm{Ni}^{2+}$ cations were completely dehydrated and coordinated to three surface oxygens of the tetrahedral sheets. Indeed, Muller et al. [30] have elegantly confirmed, using EXAFS data, that $\mathrm{Ni}^{2+}$ exchange cations continue their migration into the clay layer as the pretreatment temperature increases from 150 to $250{ }^{\circ} \mathrm{C}$, eventually taking up residence in the vacant cis-octahedra of the 2:1 layers, neutralizing the negative charge on the layer and imparting a charge-neutral, talc-like nature to the product.
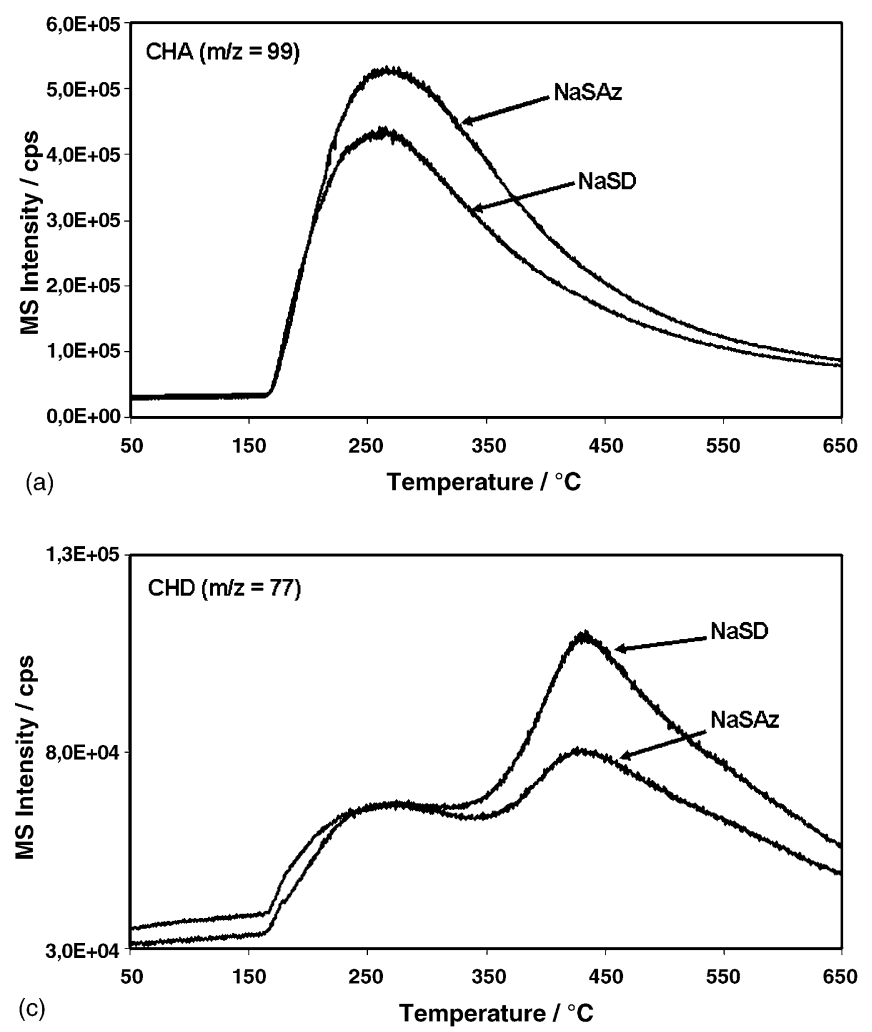

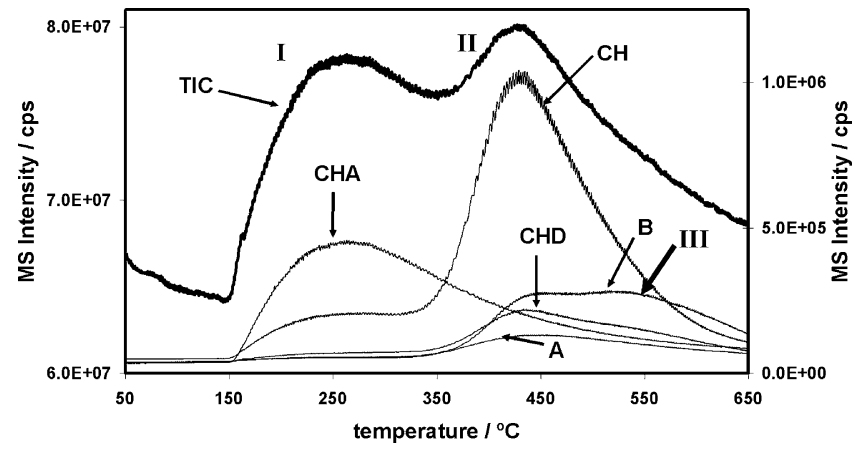

Fig. 6. Real time MS ion chromatograms for the adsorption of CHA $(\mathrm{m} / \mathrm{z}=99)$, $\mathrm{CH}(\mathrm{m} / \mathrm{z}=54), \mathrm{CHD}(\mathrm{m} / \mathrm{z}=77), \mathrm{B}(\mathrm{m} / \mathrm{z}=78)$ and aniline $(\mathrm{m} / \mathrm{z}=93)$ from $\mathrm{Al}^{3+}$. SD after a 7 day incubation period with CHA.

The limonene conversion data in Fig. 3 show that the results for $\mathrm{Al}^{3+}$-SD activated at 100 and $150{ }^{\circ} \mathrm{C}$ were directly comparable whereas the yield over the sample pretreated at $250{ }^{\circ} \mathrm{C}$ was higher indicating that the conversion over this
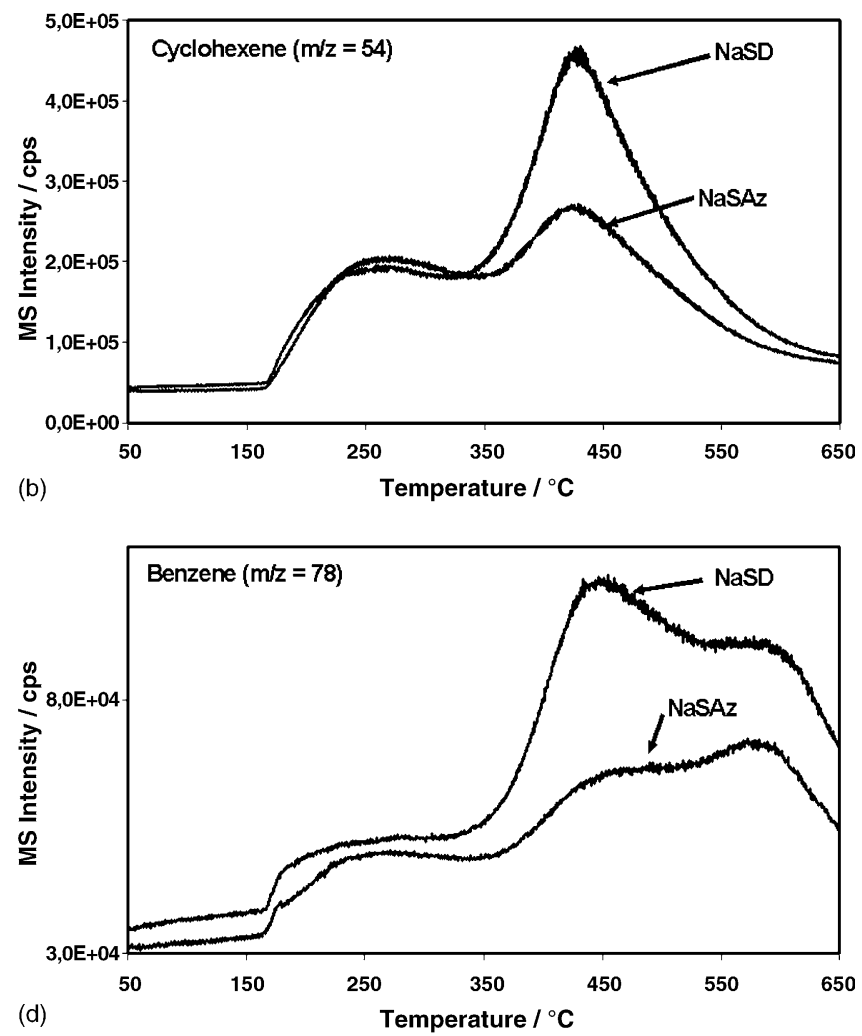

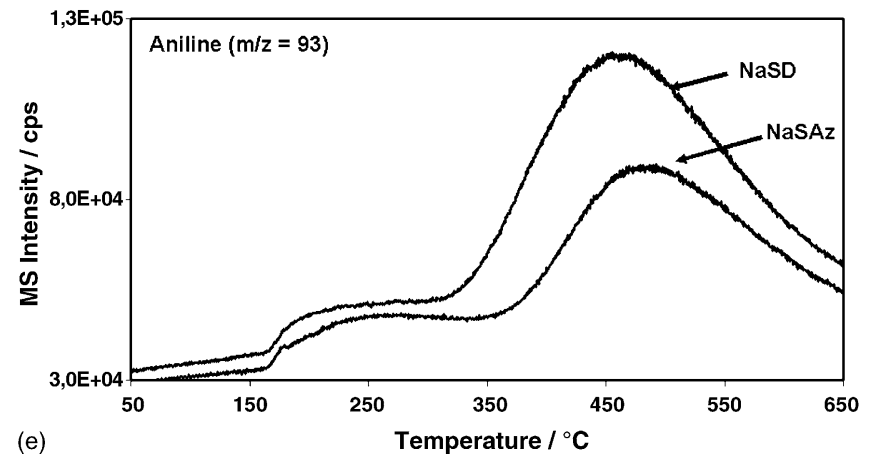

Fig. 7. Comparative MS ion chromatograms for $\mathrm{Na}^{+}-\mathrm{SD}$ and $\mathrm{Na}^{+}-$Sass. 

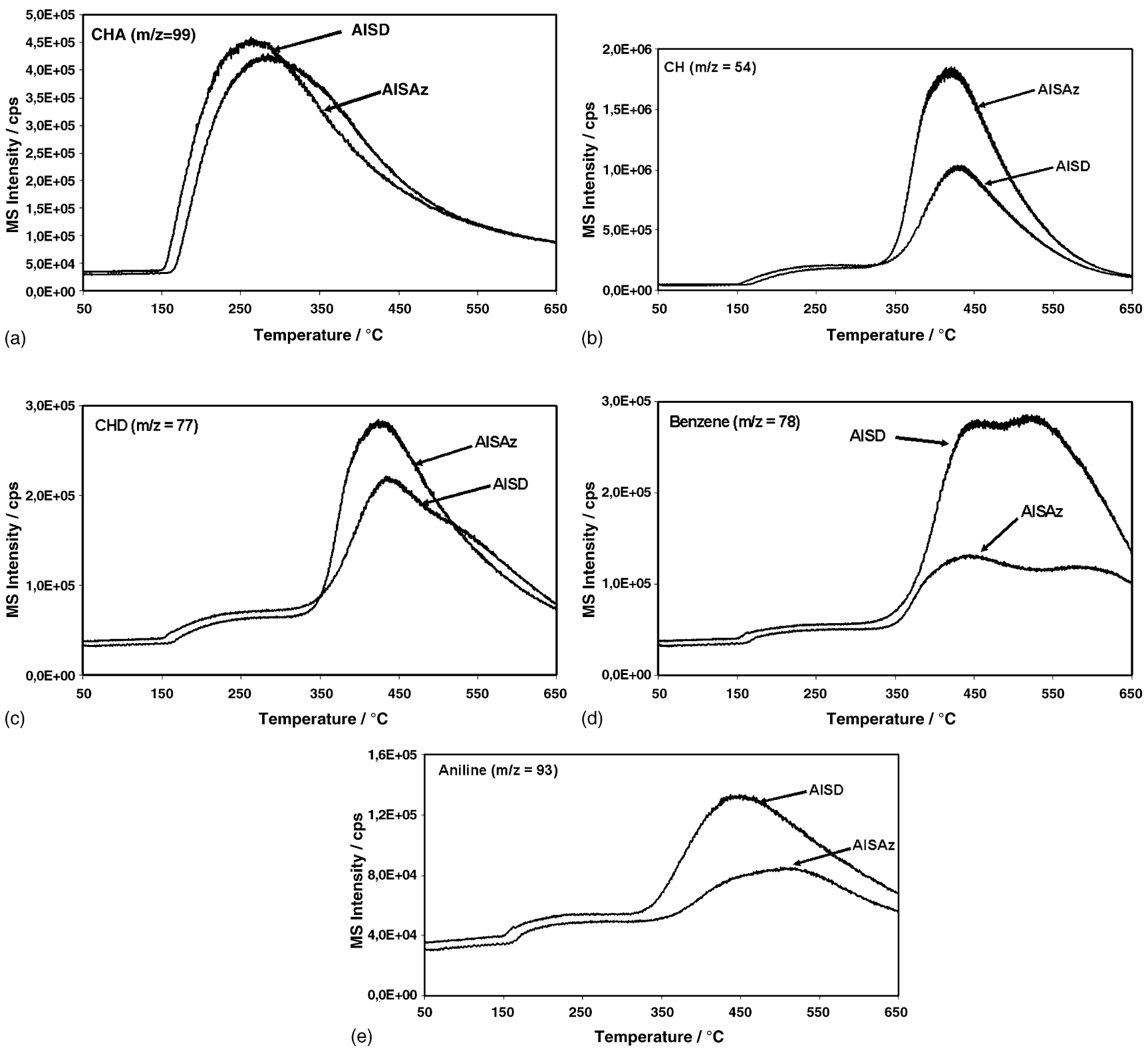

Fig. 8. Comparative MS ion chromatograms for $\mathrm{Al}^{3+}-\mathrm{SD}$ and $\mathrm{Al}^{3+}-\mathrm{SAz}$.

catalyst, in the same period, was more rapid and the system was in stage II, i.e. beyond the maximum in terpinene yield and into the region where $\alpha$ - and $\gamma$-terpinene production levels off and the $p$-cymene yield gradually increases. This enhanced activity over $\mathrm{Al}^{3+}{ }_{-} \mathrm{SD}\left(250^{\circ} \mathrm{C}\right)$, together with the higher yield over $\mathrm{Ni}^{2+}-\mathrm{SD}$, provide support for the involvement of Lewis acid sites in the production of $p$-cymene.

Unfortunately, it is difficult to assess whether the Lewis and Brönsted acid sites are situated at the edges of the clay and/or in the gallery because all the probe molecules used are able to enter the gallery and access all the available sites, whereas the partition of limonene and its transformation products, between the edges and the gallery is unknown. Consequently, the variation of $p$-cymene yield with the extent of limonene conversion was scrutinized. $\mathrm{Al}^{3+}{ }_{-} \mathrm{SD}$ and $\mathrm{Ni}^{2+}{ }_{-} \mathrm{SD}$ were selected to provide a direct comparison between a Brönsted and Lewis acid functionality. The data in Fig. 5 clearly illustrates that the gallery cation, and hence the nature of the acidity, exerted little influence on the yield of $p$-cymene. The amount of $p$-cymene produced by both cation-exchanged forms at the different limonene conversion values was identical thus testifying to the thermodynamic control of the process. Therefore, while the nature of the exchange cations significantly influenced the reaction rate, the selectivity toward $p$ cymene was not influenced by the nature of the exchange cation. Consequently, the catalytic activity data collected in this study cannot be used to determine whether Lewis or Brönsted acid sites offer a preferred route to $p$-cymene.

\subsection{Thermogravimetry-mass spectrometry (TG-MS)}

Simple thermogravimetric CHA desorption profiles provide an estimate of the number of acid sites, but they do not reveal the differences in the decomposition pathways that can occur 

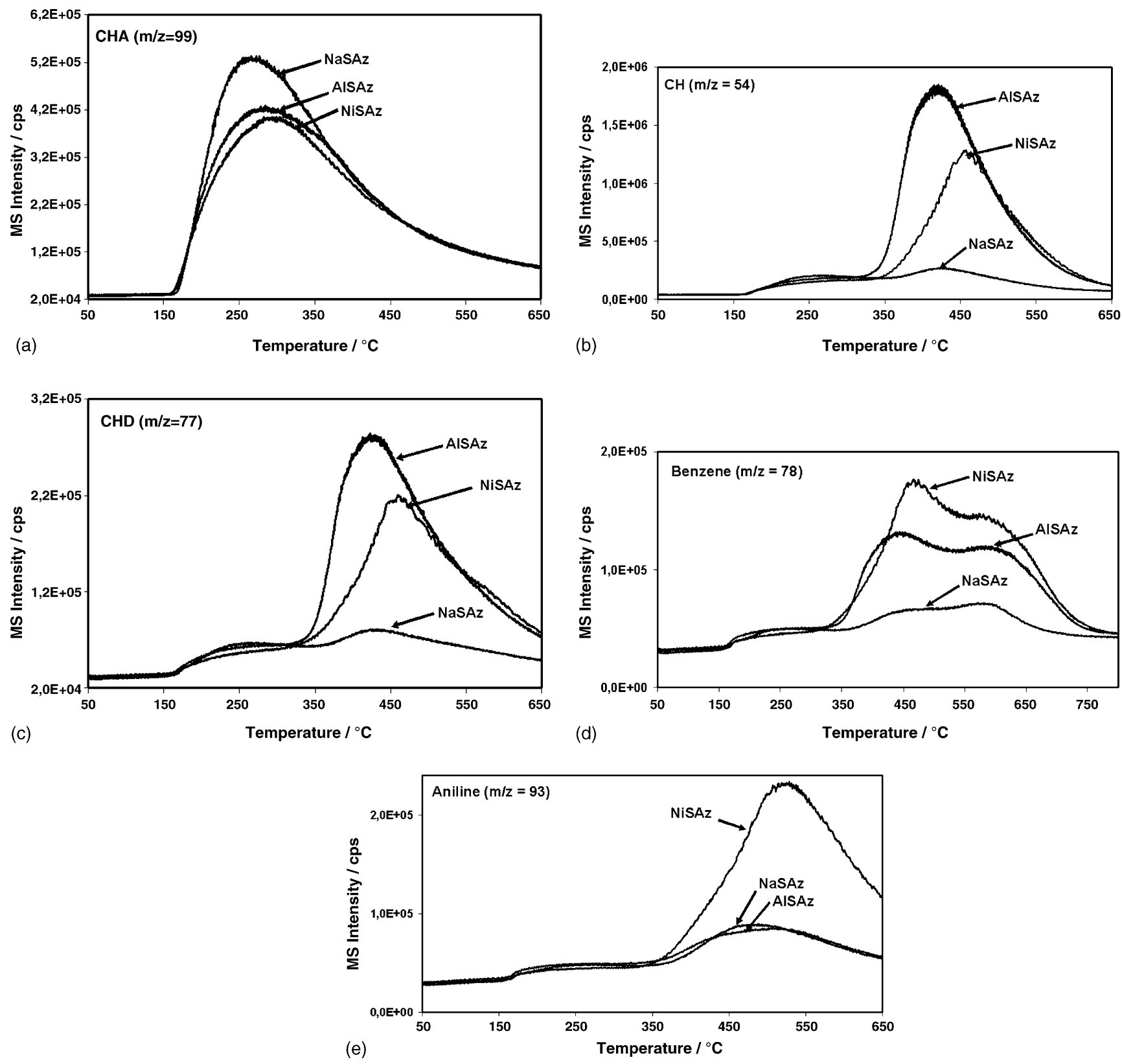

Fig. 9. Comparative MS ion chromatograms for metal exchanged Sass clays.

over different materials. As presented in a previous work [31], real time TG-MS of the decomposition products derived from CHA, provides pertinent information regarding the transformation properties of the catalyst. Generally, CHA decomposition can be represented by Scheme 2 .

Binding to a Brönsted acid site produces protonated CHA. Hofmann deamination generates unbound cyclohexene $(\mathrm{CH})$ leaving $\mathrm{NH}_{4}{ }^{+}$ions occupying some of the exchange sites. Successive dehydrogenation reactions result in the subsequent formation of cyclohexadiene (CHD) and then benzene (B). The formation of methylcyclopentene (MCP) cannot be disregarded. The presence of dehydrogenation sites was further confirmed by the appearance of aniline, which must arise from the aromatization of untransformed CHA either in the gallery or as it diffuses out of the sample. Fig. 6 illustrates the information obtained from a typical real time mass spectrum for the desorption of CHA from $\mathrm{Al}^{3+}{ }_{-} \mathrm{SD}$. The total ion count (TIC) is assigned to the left hand axis and the single ion intensities to the hand right axis.

Generally two peaks were present in the TIC profile. The peak at lower temperature (peak I) is attributed to the loss of physisorbed CHA (major component) and water and is not usually associated with clay acidity. Very small amounts of aniline were also released under peak I. The peak at higher temperature (peak II) has been routinely related to the acidity and hence the catalytic activity [14,18,26,27]. Peak II encompasses the release of a number of decomposition/ transformation products together with a little unmodified CHA. $\mathrm{CH}$ evolved first followed by $\mathrm{CHD}$ and then benzene at a slightly higher temperature. This delay in the time/temperature 

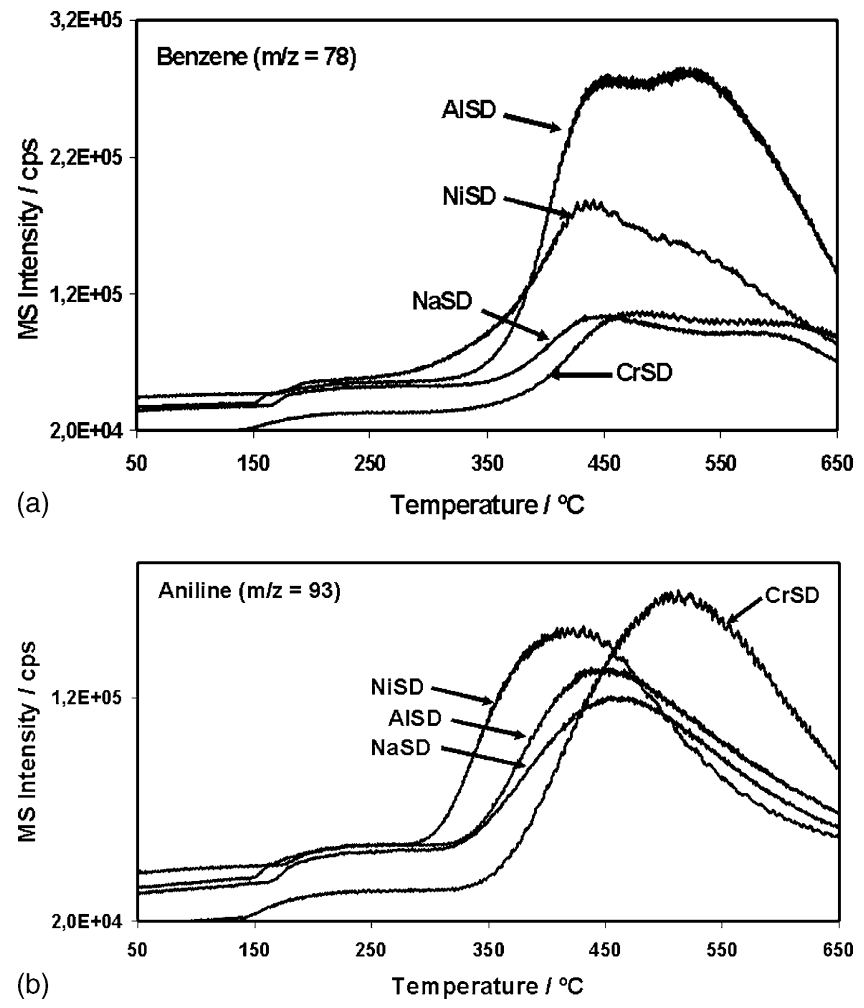

Fig. 10. Comparative MS ion chromatograms for benzene and aniline production over metal exchanged SD clay.

of $\mathrm{CHD}$ and $\mathrm{B}$ desorption may reflect the diffusion of $\mathrm{CH}$ to the ring dehydrogenation sites, transformation and then diffusion away from those sites. Significant amounts of aniline and benzene appeared at the same temperature and they both continued to be evolved to much higher temperatures than $\mathrm{CH}$ and $\mathrm{CHD}$. Nevertheless, the dehydrogenation of $\mathrm{CH}$ to benzene and CHA to aniline occurred in the same, relatively low, temperature interval. This provides some evidence for ring dehydrogenation sites, which may contribute to the production of $p$-cymene. Benzene (and aniline) was also evolved at a higher temperature (peak III) probably from the deamination of aniline, which was released at the same temperature. This will receive further consideration below.

The TG-MS data for the $\mathrm{Na}^{+}$-exchanged samples (Fig. 7) show that the MS ion intensities for the degradation products were lower than for $\mathrm{Al}^{3+}$ - and $\mathrm{Ni}^{2+}$-exchanged counterparts. $\mathrm{Na}^{+}$-SD released more $\mathrm{CH}$ and $\mathrm{CHD}$ but also more benzene and aniline, suggesting the presence of more ring dehydrogenation sites on SD than on SAz. Since acidity alone in not sufficient for the clay to act as a dehydrogenation catalyst, the structural iron (and perhaps other transition metals) could provide SD with more inherent dehydrogenation activity.

The quantities of the different degradation products desorbed from $\mathrm{Al}^{3+}{ }_{-} \mathrm{SD}$ and $\mathrm{Al}^{3+}{ }_{-} \mathrm{SAz}$ were very dissimilar (Fig. 8). Considerably more $\mathrm{CH}$ emerged from $\mathrm{Al}^{3+}-\mathrm{SAz}$ than from $\mathrm{Al}^{3+}$-SD and $\mathrm{Al}^{3+}$-SD clearly generated much more benzene and aniline than $\mathrm{Al}^{3+}-\mathrm{SAz}$. $\mathrm{CH}$ is generated directly from the rupture of the $\mathrm{N}-\mathrm{C}$ bond in $\mathrm{CHA}$. Then $\mathrm{CH}$ is transformed into CHD over ring dehydrogenation (oxidation) sites followed by further dehydrogenation to benzene, which emerges under peak II. The greater dehydrogenation activity of $\mathrm{Al}^{3+}{ }_{-} \mathrm{SD}$ is supported by the enhanced production of aniline over $\mathrm{Al}^{3+}{ }_{-} \mathrm{SD}$ compared to $\mathrm{Al}^{3+}-\mathrm{SAz}$. Of course, it is also conceivable that a small number of dehydrogenation sites with a high turnover number would provide a similar result, but the current data set is unable to distinguish between these alternate interpretations. In particular, it is important to note that aniline was produced under peak II and peak III. Aniline is produced via ring dehydrogenation of cyclohexylamine but it is not clear whether the aniline was released immediately upon its formation or whether, once formed, it is retained to higher temperature and then released. Intuitively, the latter seems more likely particularly as the galleries would have collapsed by these temperatures and the aniline was probably trapped in the space produced by adjacent ditrigonal cavities in the siloxane surface. The benzene produced under peak III was considered to arise from the deamination of a portion of the trapped aniline.

The evolution of $\mathrm{CH}$ and $\mathrm{CHD}$ from the homoionic $\mathrm{Ni}^{2+}$ clays (Figs. 9 and 10) followed similar trends to those for the Al-exchanged counterparts (Fig. 8) except that similar amounts of benzene were formed over $\mathrm{Ni}^{2+}-\mathrm{SD}$ and $\mathrm{Ni}^{2+}-\mathrm{SAz}$. It is unclear why $\mathrm{Ni}^{2+}$-saturation should work in opposite directions on SAz and SD.

Comparison of the MS ion chromatograms for the desorption of CHA from homoionic SAz (Fig. 9) shows that $\mathrm{Al}^{3+}{ }_{-} \mathrm{SAz}$ produced more $\mathrm{CH}$ and $\mathrm{CHD}$ than $\mathrm{Ni}^{2+}-\mathrm{SAz}$ and about 10 times more than $\mathrm{Na}^{+}-\mathrm{SAz}$, which agrees with the higher number of Brönsted sites present on $\mathrm{Al}^{3+}{ }_{-} \mathrm{SAz}$. However, $\mathrm{Ni}^{2+}{ }_{-} \mathrm{SAz}$ produced more benzene and aniline than $\mathrm{Al}^{3+}-\mathrm{SAz}$.

The TG-MS data provides considerable support for there being a larger number of inherently active sites, including ring dehydrogenation sites, on SD than on SAz. Subsequent modification of the two clays by ion exchange does not remove this difference but the nature of the exchange cation does alter the detailed balance between the transformation products generated by the clays. However, the transformation products are identical despite the significant differences in the nature of the acidity on the $\mathrm{Al}^{3+}$ - and $\mathrm{Ni}^{2+}$-exchanged clays. It is interesting to note that $\mathrm{Ni}^{2+}$-SAz produced more benzene and aniline than its $\mathrm{Al}^{3+}$-exchanged counterpart, which may help to explain why $\mathrm{Ni}^{2+}-\mathrm{SAz}$ was more active than $\mathrm{Al}^{3+}-\mathrm{SAz}$ for limonene conversion. The apparent contradiction in that $\mathrm{Al}^{3+}$ $\mathrm{SD}$ produces more benzene than $\mathrm{Ni}^{2+}-\mathrm{SD}$ can be explained by the fact that the sum of the amounts of benzene and aniline produced was very similar and the increased benzene production over $\mathrm{Al}^{3+}$-SD represents a more extensive Hofmann deamination of the trapped aniline in $\mathrm{Al}^{3+}$-SD than in $\mathrm{Ni}^{2+}$-SD. This could explain why the $\mathrm{Al}^{3+}$ - and $\mathrm{Ni}^{2+}$ exchanged forms of SD have similar activities in the transformation of limonene.

\section{Conclusions}

The conversion of limonene to $p$-cymene over $\mathrm{M}^{n+}$-SD increased as $\mathrm{Ni}>\mathrm{Al}>\mathrm{Cr}$. Na but, while this trend continued with $\mathrm{Ni}-\mathrm{SAz}$ being more active than Al-SAz, the overall 
activity over catalysts derived SAz was significantly weaker than over the SD counterparts. The relative inactivity of the SAz-based catalysts was attributed to the inaccessibility of the active sites on SAz and a greater inherent activity of SD, which also has a greater nitrogen surface area. No evidence was found to support the possibility that the ratio of the amount of $p$ cymene produced to the extent of limonene converted was influenced by the nature (Lewis/Brönsted) of the acid sites. The rate of production of polymeric side products over the cationexchanged clay catalysts, which retain their lamellar character, appears to be less than that when using acid-activated clays in which the lamellar nature has been severely disrupted.

Mass spectral analysis of the transformation products released from the cyclohexylamine treated catalysts provided evidence that SD offered more inherent active sites than SAz. In particular the ring dehydrogenation activity over the SD derived catalysts was greater than that over those derived from SAz.

\section{Acknowledgements}

Financial support from Fundação de Ciência e Tecnologia (Portugal) and FEDER (POCTI/CMT/47619/2002) is gratefully acknowledged. C. Fernandes is grateful for the financial support provided by the European Social Fund under PRODEP Grant No. 05.03/MD/00276.017/03.

\section{References}

[1] K.A.D. Swift, Top. Catal. 27 (2004) 143-155.

[2] V. Krishnasamy, L.M. Yeddanapalli, Can. J. Chem. 54 (1976) 3458.

[3] US Patent 2,402,898 to Hercules Powder Co.

[4] US Patent 2,272,711 to Am. Cyanamid Co.

[5] D. Buhl, P.A. Weyrich, W.M.H. Sachtler, W.F. Hölderich, Appl. Catal. A 171 (1998) 1.

[6] D. Buhl, D.M. Roberge, W.F. Hoelderich, Appl. Catal. A 188 (1999) 287.
[7] P.A. Weyrich, W.F. Hoelderich, Appl. Catal. A 158 (1997) 145.

[8] P.A. Weyrich, H. Trevino, W.F. Hölderich, W.M.H. Sachtler, Appl. Catal. A 163 (1997) 31.

[9] H. Komae, J. Sci. Hiroshima Univ. A 24 (1960) 699.

[10] M. Frenkel, L. Heller-Kallai, Clays Clay Miner. 31 (1983) 92.

[11] A. De Stefanis, G. Perez, O. Ursini, A.A.G. Tomlinson, Appl. Catal. A 132 (1995) 353.

[12] C. Fernandes, C. Catrinescu, P. Castilho, P. Russo, M. Carrott, C. Breen, in: M. Suárez, M.A. Vicente, V. Rives, M.J. Sánchez (Eds.), Materiales Arcillosos: de la Geología a las Nuevas Aplicaciones, Sociedad Española de Arcillas, Salamanca, 2006, , pp. 111-122., ISBN: 84-6896471-9.

[13] R.S. Varma, Tetrahedron 58 (2002) 1235.

[14] C. Breen, A.J. Moronta, J. Phys. Chem. B 104 (2000) 2702.

[15] U. Hofmann, R. Klemen, Z. Anorg. Allg. Chem. 262 (1950) 95.

[16] C. Breen, Clay Miner. 26 (1991) 487.

[17] D.R. Brown, C.N. Rhodes, Catal. Lett. 45 (1997) 35-40.

[18] C. Breen, A.J. Moronta, Clay Miner. 36 (2001) 467.

[19] M.P. Hart, D.R. Brown, J. Mol. Catal. A 212 (2004) 315.

[20] C. Breen, J. Forsyth, J. Yarwood, T. Hughes, Phys. Chem. Chem. Phys. 2 (2000) 2887-3892.

[21] A.U. Dogan, M. Dogan, M. Onal, Y. Sarikaya, A. Aburub, D.E. Wurster, Clays Clay Miner. 54 (2006) 62-66.

[22] R. Crockett, E. Roduner, J. Chem. Soc. Perkin Trans. 2 (1994) 347.

[23] P. Castilho, G. Faria, C. Fernandes, C. Breen, M. Carrott, I. Cansado, A. Candeias, in: Proceedings of the First Latin American Clay Conference, vol. II, 2000, p. 134.

[24] J.W. Ward, J. Colloid Interf. Sci. 28 (1968) 269-277.

[25] C. Breen, A.T. Deane, J.J. Flynn, Clay Miner. 22 (1987) 169.

[26] J.A. Ballantine, P. Graham, I. Patel, J.H. Purnell, K.J. Williams, J.M. Thomas, in: L.G. Schultz, H. van Olphen, F.A. Mumpton (Eds.), Proceedings of the International Clay Conference Denver, 1985, The Clay Minerals Society, Bloomington, IN, (1987), p. 311.

[27] P. Komadel, M. Janek, J. Medejova, A. Weekes, C. Breen, J. Chem. Soc. Faraday Trans. 93 (1997) 4207-4210.

[28] A.F. Thomas, Y. Bessiere, Nat. Product Rep. (1989) 291-309.

[29] F. Velghe, R.A. Schoonheydt, J.B. Uytterhoeven, Clay Clay Miner. 25 (1977) 375-380.

[30] F. Muller, G. Besson, A. Manceau, V.-A. Drits, Phys. Chem. Miner. 24 (1997) 159-166.

[31] C. Breen, J. Forsyth, J. Yarwood, T. Hughes, Phys. Chem. Chem. Phys. 2 (2002) 3887-3892. 